\title{
Using eTechnologies for Active Learning
}

\author{
Jo Coldwell, Annemieke Craig \& Annegret Goold \\ Deakin University, Australia
}

\author{
jo.coldwell@deakin.edu.au; annemieke.craig@deakin.edu.au; \\ annegret.goold@deakin.edu.au
}

\begin{abstract}
This paper describes a study of educators at an Australian University who are using eTechnologies in their teaching. The perceptions of the educators of the technologies are discussed as well as how they believe these technologies help students to learn. Outcomes from the study offer suggestions of how appropriate eTechnologies can be incorporated into online learning environments for effective teaching. Particular emphasis is made of eTechnologies which support active learning by students, one of the goals of the principles of good teaching practice in undergraduate education.
\end{abstract}

Keywords: eTechnologies, active learning, engagement, higher education.

\section{Introduction}

The 1980s and early 1990s provided a period of enormous change in the Australian education system. High school retention rates more than doubled during the 1980 s, increasing to $77 \%$ in 1992 (Burke \& Spaull, 2001). Changing community expectations, a depressed teenage labour market, and government policies encouraging students to complete their secondary education were all contributing factors to the increased retention (Williams, Long, Carpenter, \& Hayden, 1987). Restructuring of the Higher Education sector by the Government followed, with the aim of enabling wider participation and creating a better educated and highly skilled population (Dobson, 2001). The number of students in higher education rose dramatically in the space of twenty years. In 2009 the Department of Education, Employment and Workplace Relations (DEEWR) reported that there were a total of 978,062 students enrolled by higher education providers throughout Australia (DEEWR, 2010).

In 2008 a review of the higher education sector set new targets: the percentage of 25- to 34-yearolds completing an undergraduate degree to rise from $29 \%$ to $40 \%$ by 2020 and $20 \%$ of students enrolled in higher education to be students from low socio-economic backgrounds (Bradley, Noonan, Nugent, \& Scales, 2008). These targets reflect the view that "the reach, quality and per-

Material published as part of this publication, either on-line or in print, is copyrighted by the Informing Science Institute. Permission to make digital or paper copy of part or all of these works for personal or classroom use is granted without fee provided that the copies are not made or distributed for profit or commercial advantage AND that copies 1) bear this notice in full and 2) give the full citation on the first page. It is permissible to abstract these works so long as credit is given. To copy in all other cases or to republish or to post on a server or to redistribute to lists requires specific permission and payment of a fee. Contact HPublisher@InformingScience.orgH to request redistribution permission. formance of a nation's higher education system will be the key determinants of its economic and social progress" ( $p$. $\mathrm{xi}$.

To meet these targets the focus within the sector has moved to student engagement as well as the retention of students. Educators in traditional face-toface environments, as well as those delivering courses in wholly online or blended modes, now need to find ways 
to engage an increasingly diverse student body in a growing number of educational settings in which information and communication technologies (ICTs) are ubiquitous.

From the start of the twenty-first century universities have been quickly moving towards implementing large, institution-wide course management systems such as Blackboard suggesting that "the acquisition of knowledge remains paramount as a goal for many educators" (Herrington, Reeves, \& Oliver, 2005, p. 4). But does this support student engagement? The advent of Web 2.0 technologies has provided institutions with opportunities to engage students with their learning in new and exciting ways. Although many of the "net generation" of students are familiar with such technologies in their day-to-day activities, not all students (or educators) are technology savvy. Some students do not have access to technology while others are not interested in the technology or the functionality it can provide.

Ramaley and Zia (2005, p. 8.7) suggest new forms of technology can "enrich traditional forms of learning and serve as links between active and passive, individual and group, and transmission and generation of knowledge". However $\mathrm{Fu}, \mathrm{Wu}$, and Ho state that ICTs have "created a supportive environment for collaborative learning at the expense of student motivation and engagement" (2009, p. 550). Fisher and Baird (2006-2007) suggest that the challenge for higher education institutions is to find new pedagogies that utilize new technology-supported learning environments while meeting the needs of diverse student groups.

This paper describes a study of faculty at an Australian university who are using eTechnologies in their teaching and discusses their perceptions of how these technologies help students to learn. Outcomes from the study offer suggestions of how appropriate eTechnologies can be incorporated into online learning environments for effective teaching. Particular emphasis is made of eTechnologies which support active learning by students.

\section{Literature}

The notion of student engagement is based on the constructivist assumption that learning is influenced by how a student participates in educationally purposeful activities (Coates, 2005). According to Barkley (2010, p. 8) student engagement "is a process and a product that is experienced on a continuum and results from the synergistic interaction between motivation and active learning." Active learning is used in a number of different contexts and has a number of slightly different interpretations. Barkley (2010, p.16) suggests that active learning entails actively engaging one's mind and refers to it as "an umbrella term that ... [includes] cooperative and collaborative learning, discovery learning, experiential learning, problem-based learning and inquiry-based learning" and that this is critical to student engagement. Brown et al. (2009) propose that, based on educational theory and common sense, active learning should lead to improved learning outcomes such as the uptake and retention of information and skills.

Active learning is not a new concept. In 1987, in their foundational article, Chickering and Gamson proposed the Seven Principles for good teaching practice in undergraduate higher education:

1. Encourage contact between students and faculty

2. Develop reciprocity and cooperation among students

3. Encourage active learning

4. Give prompt feedback

5. Emphasize time on task

6. Communicate high expectation

7. Respect diverse talents and ways of learning (Chickering \& Gamson, 1987).

Sorcinelli (1991, as cited in Prebble et al., 2005) report that these principles were not only developed by distinguished researchers but were well supported by 50 years of research literature. 
Prebble et al. (2005) suggest that there are few sources as frequently cited in teaching development literature as these principles.

Active learning according to Chickering and Gamson (1987) is "not a spectator sport. Students do not learn much just by sitting in classes listening to teachers, memorizing pre-packaged assignments, and spitting out answers. They must talk about what they are learning, write about it, relate it to past experiences and apply it to their daily lives. They must make what they learn part of themselves" (p. 2).

A subsequent paper "Implementing the Seven Principles: Technology as a Lever" (Chickering \& Ehrmann, 1996) documented some of the cost-effective and appropriate ways to use ICT to advance the Seven Principles. The range of technologies to support active learning at that time was considered to be "staggering" with many technologies falling into one of three categories: asynchronous communication (time delayed exchange), synchronous communication (real-time conversation), and tools that supported learning by doing. For the latter category Chickering and Ehrmann suggested that apprentice-like learning, simulating techniques, and helping students to develop insights were all afforded by these new tools. In the last 15 years with the advent of Web 2.0, the list of technologies that support active learning continues to expand.

The Australasian Survey of Student Engagement (AUSSE), under the auspices of the Australian Council of Educational Research (ACER), is aimed at collecting data from first year and later year students in higher education institutions in Australia (ACER, 2010). The AUSSE was first used in 2007 and annually since. The survey measures six areas of student engagement including active learning. It defines active learning as "the extent to which students are involved in experiences that involve actively constructing new knowledge and understanding" (ACER, 2010, p. 17). The types of activities being measured in the Active Learning scale all involve physical activity. These include asking questions or contributing to discussions, making presentations; and working with other students. Rather than focusing on student satisfaction or agreement, as many similar surveys do, "the AUSSE provides evidence about what students are actually doing, highlights the most critical aspects of student learning and development, provides a 'learner-centered, whole-ofinstitution' perspective, and gives an index of students' involvement in both study and other relevant activities". The outcomes suggest that students' participation in active learning activities steadily increase as students mature, with later year students more actively engaged than their first year counterparts (ACER, 2010).

The challenge for the modern educator then is how to provide active learning opportunities that will engage a diverse range of students using an ever increasing range of eTechnologies now available (and remain sane through the process).

\section{The Study}

The research described here was undertaken as part of a 2010 Deakin University Strategic Teaching and Learning Grant project that sought to inform pedagogies and practice for teaching and learning online. Online teaching is an important component of Deakin University's overall pedagogical approach since the needs of diverse cohorts of students across five campuses have to be accommodated as well as the needs of off campus students who do not attend a physical campus. Further, the modern student wants "just-in-time" education, the ability to access resources anytime, anywhere and to study in a flexible manner.

The first phase of the project was an extensive profile of tools used in online teaching as described in current literature (Craig, Coldwell, \& Goold, 2011). In this, the second phase of the project, faculty from Deakin University with expertise in teaching with a particular eTechnology were identified and interviewed. The faculty were from a wide range of disciplines. Twelve 
semi-structured interviews of approximately 30 minutes were conducted face to face and were audio-taped. The audiotapes were then transcribed and the relevant responses were collated.

Interview questions sought information about the demographics of the students in the course, how the eTechnology was used in the context of teaching, how the students used the eTechnology, and what they (the faculty) perceived as the benefits and challenges of using the technology to be. Faculty were also asked to select one or more of Chickering and Gamson's (1987) Seven Principles for Good Practice that were best supported by using their particular eTechnology.

\section{Findings}

The findings from the interviews are shown in Table 1. The eTechnology categories in column 1 have been adopted from the review of the literature of eTechnologies conducted in the first phase of the project (Craig et al., 2011). The eTechnology tools shown in column 2 are the actual technologies used by faculty while the application and context (column 3 ) shows the discipline area and designates how the eTechnology was used by students. The remaining columns in Table 1 show the ratings of good practice principles by faculty with respect to the eTechnologies they had used. These were the responses to the question "With reference to the attached document (the Seven Principles for Good Practice), indicate which of the seven principles you consider this technology supports and why." Most faculty selected as many as three principles but highlighted the one they considered to be the most relevant (indicated by an asterisk in the table).

Chickering and Gamson's Seven Principles are reiterated here to aid readability:

1. Encourage contact between students and faculty

2. Develop reciprocity and cooperation among students

3. Encourage active learning

4. Give prompt feedback

5. Emphasize time on task

6. Communicate high expectation

7. Respect diverse talents and ways of learning (Chickering and Gamson, 1987).

Table 1 shows that nine of the 12 faculty indicated that active learning (Principle 3 ) was supported by their use of the eTechnology. Five of the nine faculty indicated that this principle was the most important. 


\begin{tabular}{|c|c|c|c|c|c|c|c|c|c|c|}
\hline \multirow{3}{*}{$\begin{array}{l}\text { eTechnology } \\
\text { Category }\end{array}$} & & & & & & & & & & \\
\hline & \multirow{2}{*}{$\begin{array}{l}\text { eTechnology } \\
\text { Tool }\end{array}$} & \multirow{2}{*}{\multicolumn{2}{|c|}{$\begin{array}{l}\text { Application } \\
\text { and Context }\end{array}$}} & \multicolumn{7}{|c|}{ Principles } \\
\hline & & & & 1 & 2 & 3 & 4 & 5 & 6 & 7 \\
\hline \multirow[t]{2}{*}{$\begin{array}{l}\text { Assessment and } \\
\text { Survey Tools }\end{array}$} & Quiz & \#01 & $\begin{array}{l}\text { Online Quizzes } \\
\text { Science }\end{array}$ & & & & $\sqrt{ }$ & $\sqrt{ }$ & & \\
\hline & Peer Assessment & \#02 & $\begin{array}{l}\text { Peer Group Assessment } \\
\text { Architecture }\end{array}$ & & $\sqrt{ }$ & & $\sqrt{ }$ & & & \\
\hline $\begin{array}{l}\text { Podcasts, Vodcasts } \\
\text { and Streaming }\end{array}$ & $\begin{array}{l}\text { Podcasts/ } \\
\text { Vodcasts }\end{array}$ & \#03 & $\begin{array}{l}\text { Professional Practice } \\
\text { Public Relations }\end{array}$ & $\sqrt{ }$ & $\sqrt{ }$ & $\sqrt{ } *$ & & & & \\
\hline \multirow[t]{2}{*}{ Virtual Worlds } & Online Roleplay & \#04 & $\begin{array}{l}\text { Video Scenarios } \\
\text { Nursing }\end{array}$ & & & $\sqrt{ } *$ & $\sqrt{ }$ & & & $\sqrt{ }$ \\
\hline & ESimulations & $\# 05$ & $\begin{array}{l}\text { Esimulations } \\
\text { Information Systems }\end{array}$ & $\sqrt{ }$ & $\sqrt{ }$ & $\sqrt{ } *$ & & & & \\
\hline \multirow[t]{2}{*}{$\begin{array}{l}\text { Synchronous } \\
\text { Communication }\end{array}$} & \multirow[t]{2}{*}{ ELive } & \#06 & $\begin{array}{l}\text { Student role play } \\
\text { Psychology }\end{array}$ & $\sqrt{ } *$ & $\sqrt{ }$ & $\sqrt{ }$ & & & & $\sqrt{ }$ \\
\hline & & \#07 & $\begin{array}{l}\text { Online classes } \\
\text { Property \& Management }\end{array}$ & $\sqrt{ }$ & & $\sqrt{ } *$ & $\sqrt{ }$ & & & \\
\hline Shared Documents & Google Docs & \#08 & $\begin{array}{l}\text { Team collaboration } \\
\text { Marketing }\end{array}$ & $\sqrt{ }$ & $\sqrt{ }$ & $\sqrt{ } *$ & & & & $\sqrt{ }$ \\
\hline \multirow[t]{2}{*}{ Wiki } & \multirow[t]{2}{*}{ Wiki } & \#09 & $\begin{array}{l}\text { Team collaboration } \\
\text { Architecture }\end{array}$ & & $\sqrt{ }$ & $\sqrt{ }$ & $\sqrt{ }$ & $\sqrt{ }$ & & \\
\hline & & $\# 10$ & $\begin{array}{l}\text { Team collaboration } \\
\text { Accounting \& Finance }\end{array}$ & & $\sqrt{ }$ & $\sqrt{ }$ & & & & \\
\hline Photosharing & Gallery 2 & $\# 11$ & $\begin{array}{l}\text { External peer collaboration } \\
\text { Arts }\end{array}$ & & $\sqrt{ }$ & & $\sqrt{ }$ & & $\sqrt{ }$ & $\sqrt{ }$ \\
\hline Social Networking & Facebook & $\# 12$ & $\begin{array}{l}\text { Transition \& Support } \\
\text { Law }\end{array}$ & & & $\sqrt{ }$ & $\sqrt{ }$ & & & \\
\hline
\end{tabular}

The three eTechnology tools (\#01, \#02 and \#11) that did not receive an active learning rating were:

- online quizzes used extensively in the teaching of chemistry to about 800 undergraduates;

- an online assessment tool to evaluate peer contributions in team design projects in Architecture for about 50 undergraduates; and

- the Gallery2 software that enabled Arts students to undertake collaborations and sharing of photos with peers in external institutions.

The following section of the paper will briefly define the eTechnologies which did receive an active learning rating and then describe how they were used to facilitate the active learning by students.

\section{Active Learning through Podcasts and Vodcasts}

A podcast is an audio or video file that can be downloaded to a computer or mobile device capable of playing MP3 or MP4 files. A video podcast (vodcast) refers to online delivery of video 
content on demand. Unlike audio or video streaming, the file is transferred to the device and is played locally, providing smoother delivery.

\section{The MediaPod (\#03)}

The MediaPod is a dedicated website which delivered resources to students to support studies in public relations. Podcasts and vodcasts were used in conjunction with blogging in the MediaPod to provide students with a deeper understanding of public relations journalism and communication. Interviews with leading public relations professionals were recorded and set up on the site. Students could listen to or watch these any number of times. MediaPod was created outside of the learning management system used at Deakin University to enable alumni, students, and professionals to communicate with each other through the blog. Faculty who were interviewed spoke of the importance of engaging students with real-life practitioners and the difficulty of doing this in a face-to-face environment, particularly when students could be located at a number of campuses as well as off-campus.

"I mean that is pretty much the guts of what I am trying to do - their experiential learning, getting my students out to talk to practitioners face-to-face."

\section{Active Learning through Virtual Worlds}

A virtual world is a simulated environment through which users can interact individually or with others to use and create objects. Virtual worlds include multi-user virtual environments and eSimulations and provide opportunities for interactivity with the simulation itself or with other users within the environment.

\section{The Virtual Maternity Clinic (\#04)}

The Virtual Maternity Clinic is a series of videos where four actors (expectant women) role play their visits to the maternity clinic. The videos are of about 35 minutes duration and are available online. A midwife avatar summarizes the key points and there are activities for students to complete relating to each of the videos. The videos are designed to link theory and practice and are designed to support students, particularly those who are studying off campus.

Faculty designed the Virtual Maternity Clinic to complement real-life experiences and to provide authentic learning opportunities. A major advantage is that students are not directly involved with the role play and, as such, it provides a safe, supportive environment for them to deal with confronting situations which they could otherwise find quite distressing.

"Okay, it encourages active learning in that students would access the virtual maternity clinic around when it is suitable for them ... they are in control, "cause we have that real experience on the virtual maternity clinic they can go back and learn how to manage, observe the role of the midwife, without threat, without risk."

\section{An eSimulation in a business context (\#05)}

An eSimulation was used in the teaching of information systems to very large cohorts of firstyear business students, about 3000 per year. Students worked on a detailed spreadsheet assignment where the eSimulation provided the context and business case (a chain of fashion stores) and provided the online help to guide students to a solution. The original simulation involved human actors but the simulations now have avatars or virtual characters and the voices are synthetic which allows it to be updated and modified much more easily for different cohorts of students. 
Again the faculty view was the importance of providing a realistic experience in modern day business.

"We have a lot of people [students] in outsourced business or people who are not in the business and you need to communicate with them using some other means" and it gives "a rich feeling that virtuality and reality, they blend together. It also gives them this feel of authenticity."

\section{Active Learning through Synchronous Communication}

Synchronous communication has many forms and is the closest technology-supported communication mode to face-to-face communication. It can be text or audio based and can include video, multimedia, document, and desktop sharing and is facilitated through chat rooms, instant messaging and video-conferencing. Synchronous tools are often used to facilitate communication in environments where face-to-face is not possible. Both of the applications here involve the use of Elluminate Live! or ELive as it is known at Deakin University.

\section{ELive for counselling and coaching (\#06)}

The aim of these ELive sessions was to provide students with an opportunity to role play scenarios using different coaching/counseling models. Students acted as a client or as a counselor/coach and used different processes to take a client from a behavior that was negatively affecting their life and to move them forward to a more positive state of mind. Generally these sessions involved about eight students with faculty facilitating the sessions. Faculty saw these as being of "great benefit particularly for students who are isolated and need contact with tutors or lecturers." Mention here was made of active learning in the context of encouraging students who were predominantly shy and not outspoken. The technology gave them the capacity to contribute and to avoid, or at least minimize, any feelings of intimidation at having to speak in a classroom setting.

\section{ELive for teaching property and management classes (\#07)}

Elive was used as a delivery mode in the teaching of two property development courses. Face-toface lectures and tutorials were run in seven weeks of the 12 week trimester, with online delivery through Elive lectures and self-paced tutorials for the other five weeks. Cohorts of 90 and 50 were involved over two teaching periods, with attendances at the online sessions being at least equal to the face-to-face classes. The lecturing style did change from face-of-face to Elive. It became more visual with lots of questions and polling techniques and students were often discussing major issues in groups in separate breakout rooms.

For the faculty involved it was "a big tick" for encouraging active learning because of the way the delivery allowed questioning techniques and the ability to tailor the content to the cohort.

"You allow people to say what they think and everybody gets an opportunity, and the responses are much higher than the face-to-face because people will have a go."

\section{Active Learning through Shared Documents}

There are a number of applications that enable the storing, editing, and reviewing of documents in a virtual space. This can be done collaboratively by multiple individuals, either in real time or asynchronously. Such applications go beyond simply circulating a document to those involved as there is only one version held on a central server. It is this one copy that can be edited making for much easier version control. 


\section{Google Docs to facilitate teamwork in marketing (\#08)}

About 750 students study a course in marketing management that is delivered wholly online with no face-to-face classes. Faculty involved with this course encouraged students to use Google Docs to complete team work assignments. These shared spaces were not moderated by faculty unless students asked for assistance via an online Help Desk. "Google Docs is just one of those tools that enables people to work together as they do in real life to do that while they are studying. Studying as you know is all about discourse but you can't always just do it face to face so you need things like Google Docs."

Faculty highlighted active learning by stressing the importance of students being able to relate things and "because they are building together one will put in an example from their work if they are a part-timer and another will say you know this is [in] my country too, so it's active."

\section{Active Learning through Wikis}

Wikis are a collection of editable web pages that are designed and built collaboratively by any number of users. Content can be created, edited and deleted at any time and from anywhere. Pages within a wiki can link to any other web page and be linked to from other web sites.

\section{Team collaboration in architecture (\#09)}

Wikis were used in a Building and Environmental Studies course for about 170 undergraduate students studying architecture and construction management. Teams of five students completed collaborative reports using wikis. Faculty here reported the fact that the course had become very vibrant and that the quality of the work had improved significantly since wikis were introduced. "When students can see their teammates' work it kind of pushes up the hurdle."

According to the faculty it encouraged active learning because students became engaged with each other's assignments.

"So they are not just sitting in their bedroom beavering (sic) away on their own assignment they are actually you know working with four other people. I know there might be an argument that working on a computer isn't very active but it can be active if they are engaging with other students."

\section{Team collaboration in accounting and finance (\#10)}

Wikis were introduced into an economics course in an effort to engage the 150 or so students who were studying off campus. The off-campus students got together online and discussed a real-life economics scenario (article) and worked out a response as part of the Wiki. "It was trying to engage students yes in some really, really interesting articles that had economics content". While the on campus students had face-to-face tutorial classes where they worked in groups and gave presentations on the same articles, the wikis "came about as a way to include the off campus student in that process".

Faculty argued that active learning was an outcome of using wikis "because they were having to do some research and think about some of the issues. They had these articles with some questions that prompted them to think about them and they had to really discuss it with each other".

\section{Active Learning through Social Networking}

Social networking creates online communities where people share interests and activities. Users are able to choose how they are "seen" by this community by creating profiles for themselves and can choose what information they wish to share. 


\section{Transition of first-year law undergraduates through Facebook (\#12)}

The Unit Chair of a first-year introductory Law Course introduced Facebook as an optional tool for students to communicate. The majority of the students were straight out of high school - "first year in law there is a lot of confidence needed as it is a hard transition." Initially it was only a few students wanting to chat about things but they also started discussing concepts from the class. Eventually Facebook was used by 170 of the 220 students studying the course. Through Facebook faculty could see what "the feel of the class was" and where things needed to be tailored. It was also an important medium for students who were too shy to speak up in lectures and formal face-to-face classes.

An instance of active learning was described by faculty as "someone would write a lot about what was happening in the class and they would go on to Facebook and everyone would join in on the discussion about it, so obviously this is active learning and students are reflecting on their performance."

\section{Discussion}

Much of the rationale for adopting eTechnologies to support students' learning revolves around the need to engage students with their learning. For the modern generation of students, technologies that they are familiar with and are used extensively in their day-to-day lives away from study seem to be the key to engaging them with their studies (Barkley, 2010). In the analysis of the 12 interviews it was apparent that faculty had clear ideas about what they were trying to achieve and the pedagogical value of adopting and using particular eTechnologies to meet the learning needs of the students.

The faculty interviewed were often the champions of the eTechnologies and pioneered their use at the University. In many cases these technologies were outside the Learning Management System and required extra support and resourcing, often obtained through special teaching and learning grants. Frequently, these faculty encouraged others to take up the eTechnologies. Some however have taken up eTechnologies but have discovered that ongoing other teaching commitments have diminished their capacity for continuing. It was obvious from all the interviews that online teaching, particularly when one is trying to be innovative or try something new, requires a significant commitment of time.

Many faculty spoke about the need for having assessment associated with the use of the eTechnologies so that students would use them. However others did not see that this was necessarily important. For example in Interview \#03, involving podcasts and vodcasts for the PR undergraduates, "I make this technology available to students who do want to embrace it ... so I really provide added resources for students who are keen to get a deeper understanding of PR journalism and communication." This was also true for Interview \#04 - "I see the Virtual Maternity Clinic as a way of enhancing learning and that is supported by what students are saying to me." Some students were reticent about using the technology and faculty reported that it was sometimes a big task as "they are wrestling with the new technology as well as with new material which they are all trying to learn" (\#03).

Where eTechnologies have been used over a period of time there have been changes to the technologies themselves as well as to how they are being used. Many faculty spoke about the evolution of their technology. In some cases the nature of the technology changed. For example in simulations for the information systems course (\#05), early simulations were based on technologies using human actors. These have now (in 2010) been replaced by simulations using avatars and virtual characters with synthetic voices. In other cases faculty were willing to extend capability since "we have become more familiar with the software and comfortable using it and you try and extend your skills and offerings so that it is a bit different" (\#07). 
It is apparent from the findings that faculty have different ideas about what active learning is and how it is manifested in student behavior. For some faculty, active learning is a means of giving students a real-life experience through the use of simulations, virtual worlds, and podcasts and vodcasts of professionals in the field. For others, students being actively engaged with their peers or students using questioning and reflecting techniques were evidence of active learning. Active learning was also evidenced by shy students who did not participate in face-to-face classes but who were responsive using technologies such as ELive, synchronous communication or a blog. These different views of what constitutes active learning aligns well with the AUSSE (ACER, 2010).

Of the nine cases presented here as examples of supporting active learning, six were also selected by faculty as supporting Chickering and Gamson's (1987) second principle "Develops reciprocity and cooperation among students"; five cases supported the first principle "Encourage contact between students and faculty"; and four cases supported principle four "Gives prompt feedback" (see Table 1). All these secondary principles revolve around communication between students and staff and within the student body, and cooperation between students. Engagement therefore is not only engaging with the learning but engaging with peers and educators to extend and enhance learning.

\section{Conclusions}

There is evidence to support the notion that active learning is facilitated by using eTechnologies, particularly where students are comfortable with using the technology or where they feel less intimidated to actively participate online compared to a face-to-face environment. Here we have described nine case studies of different courses where the diverse range of eTechnologies were adopted and used. In all nine cases, the faculty interviewed nominated Chickering and Gamson's third principle, encourage active learning, as being facilitated through the use of the eTechnology. Further, there is evidence that active learning was facilitated by the eTechnologies that supported communication and collaboration and through online learning activities that were facilitated by using the eTechnologies.

A limitation of this study is that it is simply a snapshot of use of eTechnologies at one particular university in 2010. The innovative use of eTechnologies was often supported through teaching and learning grants rather than as part of the mainstream institutional infrastructure to support teaching and learning. This suggests that future innovations are reliant on the continued availability of such grants and the technology being mainstreamed and fully supported by the institution.

Even as new technologies are being developed it is important to keep abreast of these to be able to gain the benefits they can offer to both teacher and learner. However, incorporating new technologies in innovative ways into a teaching portfolio requires time and effort on the part of the innovator. Thus it is important that sufficient time is allocated for staff to be able to experiment and implement these effectively and successfully. Further, the speed with which technologies come and go suggests that the study could be repeated quite regularly with differing outcomes.

Chickering and Ehrmann's (1996) range of technologies to support active learning has now expanded with eTechnologies being utilized in different ways to engage students and to encourage and support their learning. This is reinforced by the AUSSE findings relating to active learning which entails 'active participation' rather than the more esoteric view perhaps of engaging one's mind (a reflection on the learning needs of the modern student?). This paper has provided examples of use of eTechnologies in eight categories, rather more than the original three mentioned by Chickering and Ehrmann.

Further interviews have been undertaken of faculty using eTechnologies in a number of other categories not included here. One of these categories is the eTechnologies available within the 
Learning Management System. Another category is the group of specialized eTechnologies such as Second Life. The third category is the group of eTechnologies that support management and administration of teaching and learning, such as Turnitin and SMS. Findings from these interviews will be analyzed and published in due course.

Overall this paper contributes to an improved understanding of eTechnologies and their usefulness in providing realistic and active learning opportunities for students who are studying online or who require extra assistance through online resources. The examples provided here indicate that the diverse needs of students to encourage engagement can be supported through the judicious use of appropriate eTechnologies.

\section{References}

ACER. (2010). Doing more for learning: Enhancing engagement and outcomes. Australasian Survey of Student Engagement (AUSSE), Retrieved October 2010 from http://ausse.acer.edu.au/images/docs/AUSSE_2009_Student_Engagement_Report.pdf

Barkley, E. F. (2010). Student engagement techniques: A handbook for faculty. San Francisco: Jossey-Bass.

Bradley, D., Noonan, P., Nugent, H., \& Scales. B. (2008). Review of Australian Higher Education: Final Report. Commonwealth of Australia. Retrieved October 2010 from http://www.deewr.gov.au/HigherEducation/Review/Documents/PDF/Higher\%20Education\%20Revie w_one $\% 20$ document $02 . p d f$

Brown, T., Zoghi, M., Williams, B., Jaberzadeh, S., Roller, L., Palermo, C., et al. (2009). Are learning style preferences of health science students predictive of their attitudes towards e-learning? Australasian Journal of Educational Technology, 25(4), 524 - 543.

Burke, G., \& Spaull, A. (2001). Australian schools: Participation and funding 1901 to 2000. 1301.0 - Year Book Australia, 2001. Australian Bureau of Statistics. Retrieved September 2010 from http://www.abs.gov.au/Ausstats/abs@.nsf/0/A75909A2108CECAACA2569DE002539FB?Open

Chickering, A., \& Ehrmann, S. C. (1996). Implementing the seven principles: Technology as lever. American Association for Higher Education Bulletin, 3-6. Retrieved October 2010 from http://www.tltgroup.org/programs/seven.html

Chickering, A. W., \& Gamson, Z. (1987). Seven principles for good practice in undergraduate education. American Association for Higher Education Bulletin. March

Coates, H. (2005). The value of student engagement for higher education quality assurance. Quality in Higher Education, 11(1), 25-36.

Craig, A., Coldwell, J. \& Goold, A. (2011). ETechnologies: A profile of tools for learning and teaching online. Deakin University. Internal Report.

DEEWR. (2010). Selected higher education statistics. Australian Government. Retrieved Nov10 www.deewr.gov.au/HigherEducation/Publications/HEStatistics/Publications/Pages/Students.aspx

Dobson, I. R. (2001). How has massification changed the shape of Australian universities? Tertiary Education and Management, 7(4), 295-310.

Fisher, M., \& Baird, D. E. (2006 - 2007). Making mLearning work: Utilizing mobile technology for active exploration, collaboration, assessment and reflection in higher education. Journal of Educational Technology Systems, 35(1), 3-30.

Fu, F., Wu, Y., \& Ho, H. (2009). An investigation of coopetitive pedagogic design for knowledge creation in web-based learning. Computers \& Education, 53(3), 550 - 562.

Herrington, J., Reeves, T. C., \& Oliver, R. (2005). Online learning as information delivery: Digital myopia. Journal of Interactive Learning Research, 16(4), 353 - 367. 
Prebble, T., Hargraves, H., Leach, L., Naidoo, K., Suddaby, G., \& Zepke, N. (2005). Impact of student support services and academic development programmes on student outcomes in undergraduate tertiary study: A synthesis of the research. Report to the Minister.

Ramaley, J., \& Zia, L. (2005). The real versus the possible: Closing the gaps in engagement and learning. In D. G. Oblinger \& J. L. Oblinger (Eds.), Educating the net generation (pp. 8.1-8.21): EDUCAUSE.

Sorcinelli, M. D. (1991). Research findings on the seven principles. New Directions for Teaching and Learning, 47, 13-25.

Williams, T., Long, M., Carpenter, P., \& Hayden, M. (1987). Year 12 in the 1980's. Canberra: Australian Council for Educational Research, Department of Employment, Education and Training, Australian Government Publishing Service.

\section{Biographies}

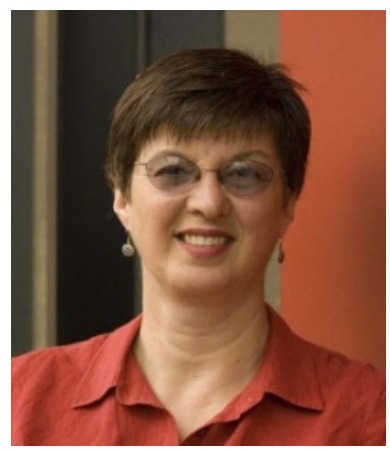

Dr Jo Coldwell joined Deakin in 1997 where she is currently Associate Head (Teaching and Learning) in the School of Information Technology. Before joining Deakin she gained a wealth of experience in both academia (in Australia) and industry (in both Australia and the UK). Since 2000 she has taught extensively online and her research interests lie in a number of areas associated with engaging tertiary teachers and learners in and with technology.

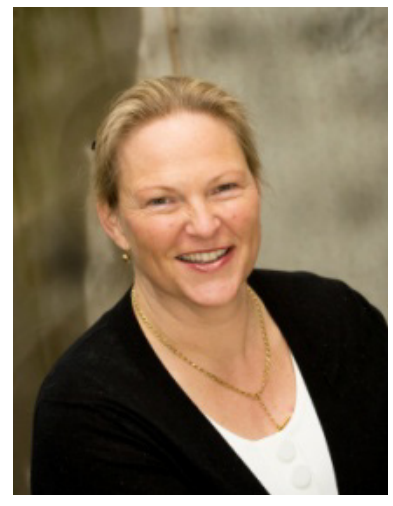

Dr Annemieke Craig is an Associate Professor in Information Systems in the Faculty of Business and Law. Annemieke's research interests include online learning and the use of technology in teaching and learning in higher education. Annemieke also researches in the fields of access and equity with particular emphasis on trying to improve the profile of women in computing and to encourage more female students to consider computing courses.

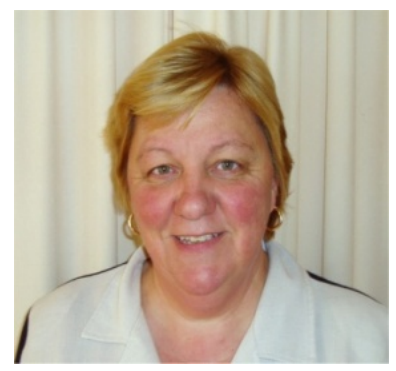

Annegret Goold is currently a research assistant in the School of Information Technology at Deakin University, Australia. Prior to 2010 she was a lecturer at Deakin, and taught introductory IT, computer programming, project management and IT practice, and supervised projects in the capstone course. Annegret's main research areas are in online teaching and learning and the use of eTechnologies in higher education. 